\title{
Effect of Seismic P-Waves Propagation on Circular Tunnels in Layered Ground
}

\author{
Amr Ibrahim, Osman Ramadan, Adel Akl
}

\begin{abstract}
During propagation of the compression seismic $P$-waves, the tunnels are subjected to ovaling deformations. In cases where the soil stiffness is varying along the tunnel cross-section, tunnel lining may take sharper deformed shapes and subjected to magnified bending moments and thrust forces. This paper investigates the effect of the soil stratification on the seismic behavior of circular tunnels under P-waves loading. A $2 D$ finite element models with time history earthquake (EQ) analysis were performed accounting for different tunnel/soil interface slippage conditions. The finite element analysis results were compared with recent analytical solution for calculating the seismic forces of the tunnel lining. The study proved that soil stratification has a great effect on the tunnel seismic forces and it should be considered in the analysis and design. Illustrative curves were presented in this paper to give approximate magnification factors for the anticipated forces. It should be used as a guide in the preliminary design stage.
\end{abstract}

Keywords: Soil Stratification, Seismic P-Waves, Circular Tunnel, Earthquake Loads.

\section{INTRODUCTION}

Propagating of seismic compression P-waves in a direction perpendicular to the tunnel longitudinal axis, results in ovaling deformations of the tunnel lining cross-section [26]. Loads induced by vertical propagation of these waves are similar to surface surcharge load action. It is common in the design to assume that tunnels are embedded in single homogeneous soil even when the soil has slight differences in the geotechnical properties. Tunnels may be excavated or constructed in stratified soil with large difference in the stiffness. In such cases, seismic behavior of the tunnels will be more sensitive and the effect on tunnel lining forces should be addressed. It is common to provide rock anchors and thicker shotcrete lining for the tunnels where it passing in stratified rock to sustain the geostatic loads [7]. In case of earthquake loadings, these extra supports will be more important. The seismic response for tunnels in spatial variable ground motion is an important issue and should be considered in the tunnel design [9]. Several studies have been

Revised Manuscript Received on December 30, 2019.

* Correspondence Author

Amr Ibrahim, Senior Bridge/Structural Engineer, Omrania \& Associates, Saudi Arabia.

Osman Ramadan, Professor, Structural Engineering, Cairo University, Giza, Egypt.

Dean, Higher Technological Institute, Tenth of Ramadan City, Egypt.

Adel Akl, Professor, Structure Analysis and Mechanics, Cairo University, Giza, Egypt.

(C) The Authors. Published by Blue Eyes Intelligence Engineering and Sciences Publication (BEIESP). This is an open access article under the CC BY-NC-ND license (http://creativecommons.org/licenses/by-nc-nd/4.0/) performed on seismic analysis for tunnels in stratified soil Previously under transverse S-waves was assuming no-slip interface condition [2],[3]. These studies highlighted the importance of the soil stratification effect on the tunnel design. It was found that tunnel lining forces increased up to 5 times when the layers interface crossing the tunnel lining at the invert level when the upper layer was stiffer than the lower layer by 20 times [3]. Hong Wang [2] mentioned that the seismic analysis of tunnels embedded in stratified soil with different soil-lining interface conditions or real interface condition should be investigated. Kouretzis et al. [4] proposed a new set of analytical expressions to calculate the tunnel liner forces due to seismic P-wave propagation. The analytical solutions mostly assume two extreme slippage conditions (No-Slip and Full-Slip) in modeling the tangential behavior of the soil/lining interface [8]. The analytical solution assumes homogenous and elastic properties for the soil. In this study, the effect of the soil stratifications on the performance of circular tunnels- under seismic P-waves with different interface slippage conditions- is investigated. The analysis results were compared very well with the analytical solution results.

\section{MODEL DESCRIPTION}

2D finite element analysis for circular tunnels embedded in multi-layered soil conditions was carried out. ABAQUS/Standard finite element code [1] was employed for the analyses, as it possess several contact simulation techniques.

Fig. 1 describes the basic model geometry and the applied pressure loading. Elastic beam element (type= B21) was adopted to model the tunnel liner. Elastic plane strain element (type $=$ CPE4) were used to model the soil medium. Infinite elements (type=CINPE4) were introduced at the top and bottom parts of the model. Infinite element can function as an absorbing boundary in wave propagation problems to avoid wave reflection [5].

TABLE I summarizes the soil properties, P-wave loading and the geometric properties of the tunnel used in the analysis models. The pressure loading 1.6 MPa was calculated based on earthquake magnitude $\mathrm{Ms}>5.5$ and peak ground velocity of $0.379 \mathrm{~m} / \mathrm{s}$ for rock soil layers [4]. The pressure loading assumed constant for all soil layers stiffness. 


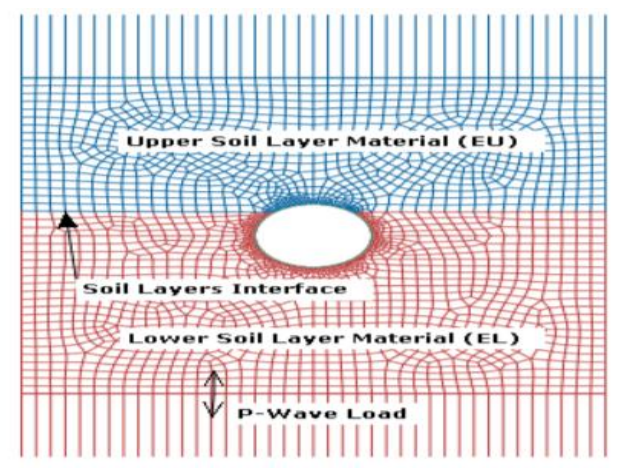

Fig.1 Finite element model: elements meshing and input $\mathbf{P}$-wave load.

Full-slip and No-slip conditions were simulated by using the contact interaction features which built in ABAQUS software. The normal behavior was defined by implementing a hard contact formulation with no-separation allowed (contact pressure or tensile stress is possible) between the tunnel outer surface and soil surface.

TABLE I : Input Data of the Example Case Study

\begin{tabular}{|c|c|}
\hline \multicolumn{2}{|l|}{ Ground Mass Properties } \\
\hline Modulus of elasticity, Es & $\begin{array}{l}\text { (A) 10, (B) 250, (C) 500, } \\
\text { (D) } 1000 \mathrm{MPa}\end{array}$ \\
\hline Poisson ratio, $v$ & 0.30 \\
\hline Soil Density, $\rho$ & $2.0 \mathrm{Mg} / \mathrm{m}^{3}$ \\
\hline \multicolumn{2}{|l|}{ Liner Properties } \\
\hline Modulus of elasticity, $E_{1}$ & $19 \mathrm{GPa}$ \\
\hline Tunnel radius, $\mathrm{r}$ & $4.0 \mathrm{~m}$ \\
\hline Poisson ratio, $v_{l}$ & 0.2 \\
\hline Thickness, t & $0.15,0.45 \mathrm{~m}$ \\
\hline \multicolumn{2}{|l|}{ Seismic Excitation } \\
\hline Peak seismic stress $\sigma_{\max }$ & $1.60 \mathrm{MPa}$ \\
\hline
\end{tabular}

Dynamic implicit analysis has been performed for all models with initial, minimum, and maximum time increments of $10^{-6}, 10^{-12}$, and $10^{-2}$, respectively.

\section{ANALYSIS MODELS USING P-WAVE PRESSURE LOADING}

The first set of analysis models were performed by applying vertical pressure loading on the bottom boundary of the soil medium to simulate the $\mathrm{P}$-wave vertical propagation. The soil media size in these analyses is $40 \times 40 \mathrm{~m}$.

Full-slip and No-slip ground/tunnel interface conditions were adopted to investigate the effect of the slippage conditions on the seismic forces increments. Preliminary analyses were carried out to address the most unfavorable location of the soil layers interface. It was found that soil layers interface when cross the tunnel at the crown gives the maximum increments in the seismic forces. So, only crown location was considered in this set of analysis.

\section{ANALYSIS MODELS USING EARTHQUAKE TIME HISTORY ANALYSIS}

The second set of analysis models were performed under the application of earthquake time history vertical acceleration for KOYNA earthquake (See Fig 2) magnitude of 6.5 on the Richter scale on December 11, 1967 [1]. The soil media in this set of analysis was enlarged to be $60 \mathrm{~m}$ width by $40 \mathrm{~m}$ height in order to achieve more accurate models.

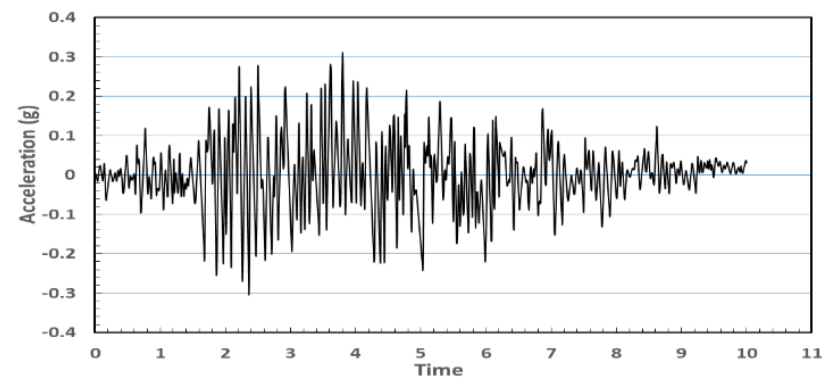

Fig 2. KOYNA Earthquake vertical acceleration

Two soil layers with different stiffness were considered in the study with five profiles. Soil Type B represents the softer soil layer while soil type D is the stiffer layer. Fig. 3 shows the soil layers' configuration for profile 1 in which the top layer is type $B$ and the depth of lower layer $\mathrm{D}$ varies from $\mathrm{y} / \mathrm{H}$ of 0.21 to 0.81 .

Where:

$\mathrm{H}$ : is the total depth of the soil layers

$y$ : depth of the lower layer or location of the layers interface from the bottom.

In Profile 2 soils B and D are reversed. The basic or reference soil type in profile 1 is type $B$.

Fig. 4 shows the soil layers' structure for profile 3 . In this soil profile, basic soil type in all models is type B and location of intermediate soil layer type $\mathrm{D}$ varies from $\mathrm{y} / \mathrm{H}$ of 0.36 to 0.81 . The intermediate layer thickness is $2 \mathrm{~m}$.

Profile 4 is similar to profile 3 with reversing the upper and lower soil types. The basic soil type in all models is type D and the depth of lower soil layer type B is variable. Profile 5 is similar to profile 2 with changing the full-slip interface condition to No-slip condition.

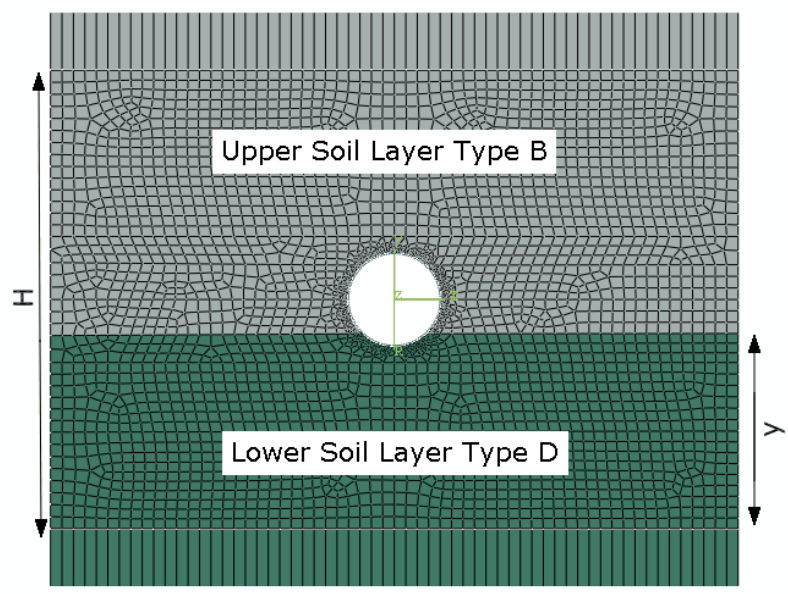

Fig. 3. Finite element model: Soil layers Profile 1 


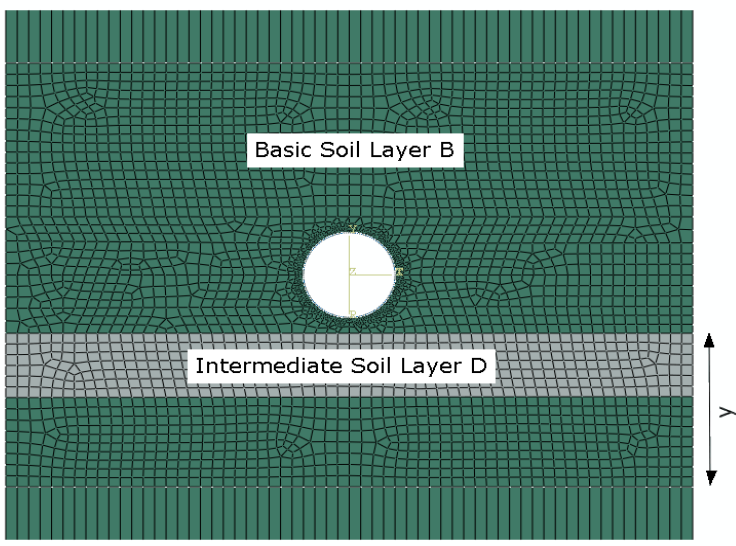

Fig. 4. Finite element model: Soil layers Profile 3

\section{RESULTS AND DISCUSSION}

In Table-II the numerical analysis results are compared to the calculated seismic thrust force and bending moment based on closed-form solution proposed by Kourtzis [4] (See Appendix A).

\begin{tabular}{|c|c|c|c|c|}
\hline \multicolumn{5}{|c|}{$\begin{array}{c}\text { Table-II: Comparison of Numerical and Analytical } \\
\text { Results in Terms of Maximum Bending Moments } \\
\text { and Thrust Forces }\end{array}$} \\
\hline $\begin{array}{l}\text { Slippage } \\
\text { Condition }\end{array}$ & $\begin{array}{l}\text { Numerical } \\
\text { Solution } \\
\text { Mmax }\end{array}$ & $\begin{array}{l}\text { Kouretzis } \\
\text { Analytical } \\
\text { Solution } \\
\text { Mmax }\end{array}$ & $\begin{array}{l}\text { Numerical } \\
\text { Solution } \\
\text { Nmax }\end{array}$ & $\begin{array}{l}\text { Kouretzis } \\
\text { Analytical } \\
\text { Solution } \\
\text { Nmax }\end{array}$ \\
\hline \multirow[t]{2}{*}{ Full-Slip } & 26.9 & 25.6 & 2979 & 2957 \\
\hline & & $(-4.8 \%)^{c}$ & & $(-0.73 \%)$ \\
\hline \multirow[t]{2}{*}{ No-Slip } & 22.3 & 19.7 & 6125 & 6023 \\
\hline & & $(-11.66 \%)$ & & $(-1.66 \%)$ \\
\hline
\end{tabular}

From the results shown in Table-II, it can be concluded that the analytical solution results in terms of thrust forces are in good agreement with the numerical predictions with differences of less than $2 \%$ for thrust forces and less than $12 \%$ for bending moments. Most the previous studied which validated the closed form solution using numerical analysis were verified that bending moments resulting from numerical analysis models are less than closed form solutions [4], [5], [10]. Hence, the differences shown in bending moment is accepted since it agreed with the previous studies.

Tables III and IV summarize the results for the numerical analysis models under the application of seismic vertical pressure loading. $E_{\mathrm{L}}$ and $\mathrm{E}_{\mathrm{u}}$ represent the soil types for the lower and upper ground layers, respectively. First, second, and fifth rows in the table show the single layer results. $R_{A}$ is a magnification factor equal to maximum bending moment value result from two layers model divided by result from single layer model with soil type A as per (1). Similarly, $R_{B}$ and $R_{D}$ are the magnification factors as per (2) and (3), respectively.

$$
R_{A}=\frac{M}{M_{A}}
$$

$$
\begin{gathered}
R_{B}=\frac{M}{M_{B}} \\
R_{D}=\frac{M}{M_{D}}
\end{gathered}
$$

Where

M: bending moment for tunnels in two-layered soil

$\mathrm{M}_{\mathrm{A}}$ : bending moment for tunnel analyzed with single layer soil Type A

$\mathrm{M}_{\mathrm{B}}$ : bending moment for tunnel analyzed with single layer soil Type B

$\mathrm{M}_{\mathrm{D}}$ : bending moment for tunnel analyzed with single layer soil Type D

From Table-III it can be concluded that magnification factor $\mathrm{R}_{\mathrm{A}}$ for maximum bending moment is approximately 3 . And for the thrust forces is 2. From Table-IV the magnification factors are less than table III which reveal that tunnels with thicker liner are less sensitive to the soil stratification.

Fig. 5 to Fig. 8 show the analysis results for the time history earthquake analysis. The figures show that worst scenario is when the upper layer are more stiff than lower layer and the layers interface crossing the tunnel lining near the crown. One can notice that, the critical location for the layers interface in case of shear waves lading was found at the invert level as mentioned in section I. Bending moments in such scenario increased to 3 times in comparison with the single layer model results while the thrust forces are increased by $40 \%$ only which indicates that trust forces are less sensitive to soil stratification. In Fig. 6, it can be seen that magnification factors for the models considering No-slip slippage condition are more than those of models with Full-slip condition. Fig. 7 and Fig. 8 show that models results for tunnel built in basic stiff ground and intermediate thin soft soil layer intercept the tunnel at different locations. In Fig. 8 it can be seen that the increments in the maximum bending moments are almost $80 \%$ more than single stiff layer and $60 \%$ for the maximum thrust forces.

\begin{tabular}{|l|c|c|c|c|}
\hline \multicolumn{5}{|c|}{$\begin{array}{c}\text { Table-III: numerical results in terms of } \\
\text { maximum thrust forces and Bending }\end{array}$} \\
moments-full-slip condition and crown interface \\
location b b
\end{tabular}


Table-IV: numerical results in terms of maximum thrust forces and Bending moments-full-slip condition and crown interface location ${ }^{\mathrm{ab}}$

\begin{tabular}{|c|c|c|c|c|}
\hline \\
\hline $\begin{array}{c}\text { Soil } \\
\text { Layers }\end{array}$ & $\mathbf{E}_{\mathbf{L}}$ & $\mathbf{E}_{\mathbf{U}}$ & $\begin{array}{c}\text { Bending } \\
\text { Moment } \\
\mathbf{M}_{\max }\end{array}$ & $\begin{array}{c}\text { Thrust Force } \\
\qquad \mathbf{N}_{\max }\end{array}$ \\
\hline $\begin{array}{l}\text { Single } \\
\text { layer }\end{array}$ & A & A & 1997 & 3491 \\
\hline $\begin{array}{l}\text { Single } \\
\text { layer }\end{array}$ & $\mathrm{D}$ & $\mathrm{D}$ & 83 & 2433 \\
\hline $\begin{array}{c}\text { Two } \\
\text { Layers }\end{array}$ & A & D & $\begin{array}{c}3336 \\
(1.7)^{c}\end{array}$ & $\begin{array}{l}7276 \\
(2.1)\end{array}$ \\
\hline $\begin{array}{l}\text { Two } \\
\text { Layers }\end{array}$ & D & A & $\begin{array}{c}91 \\
(0.05)\end{array}$ & $\begin{array}{c}955 \\
(0.27)\end{array}$ \\
\hline $\begin{array}{l}\text { Single } \\
\text { layer }\end{array}$ & B & B & 299 & 3059 \\
\hline $\begin{array}{l}\text { Two } \\
\text { Layers }\end{array}$ & A & B & $\begin{array}{l}3233 \\
(1.6)\end{array}$ & $\begin{array}{l}6564 \\
(1.9)\end{array}$ \\
\hline $\begin{array}{l}\text { Two } \\
\text { Layers }\end{array}$ & B & A & $\begin{array}{c}244 \\
(0.12)\end{array}$ & $\begin{array}{c}1010 \\
(0.30)\end{array}$ \\
\hline
\end{tabular}

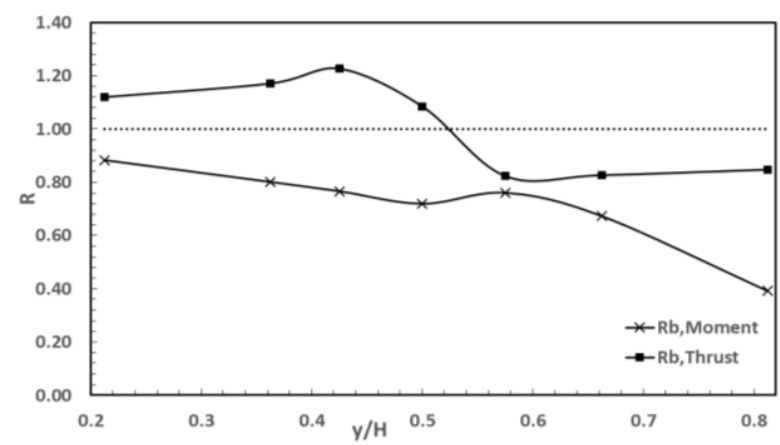

Fig. 5. Tunnel lining maximum bending moment and thrust force for Profile (1) of soil layers. (EQ time history analysis)

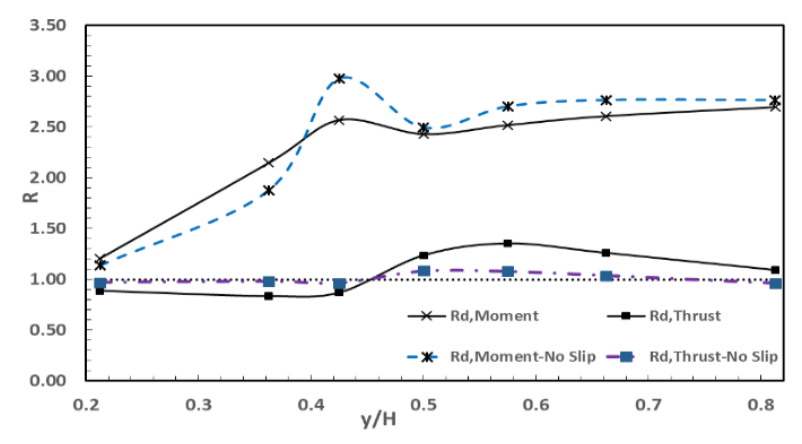

Fig. 6. Tunnel lining maximum bending moment and thrust force for Profiles ( 2 and 5 ) of soil layers (EQ time history analysis)

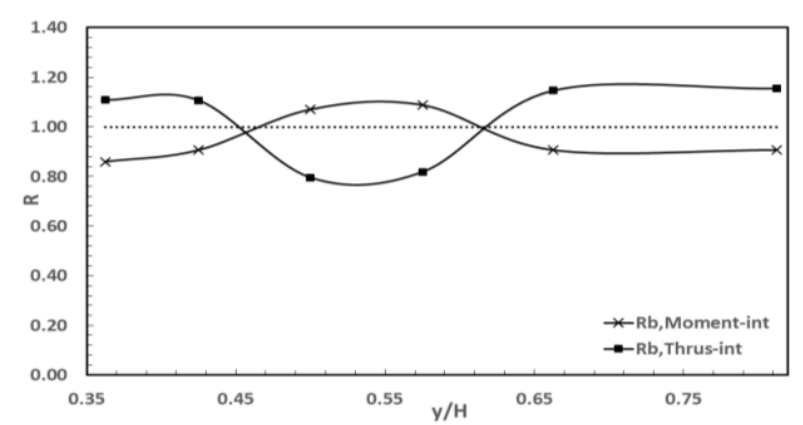

Fig. 7. Tunnel lining maximum bending moment and thrust force for Profile (3) of soil layers. (EQ time history analysis)

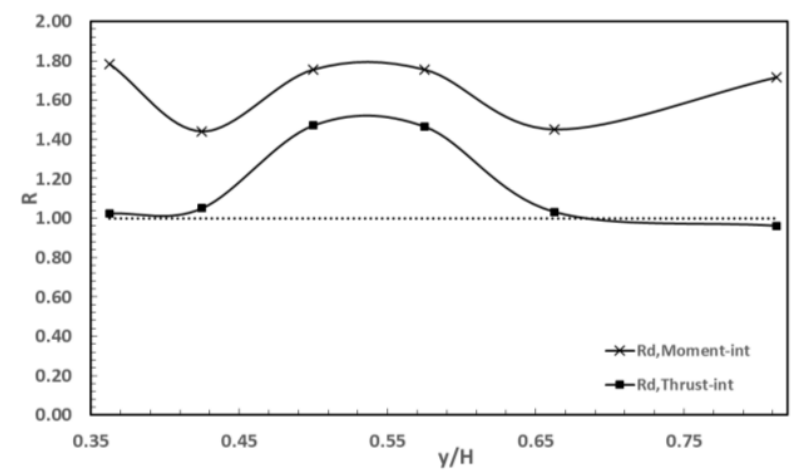

Fig. 8. Tunnel lining maximum bending moment and thrust force for Profile (4) of soil layers. (EQ time history analysis)

\section{CONCLUSION}

In this study, the seismic performance for circular tunnel subjected to vertically propagated $\mathrm{P}$-waves loading and built in stratified ground have been investigated numerically. Two sets of analysis were performed. In the first set of analysis, the P-wave loading were simulated by vertical pressure loading to allow comparison with the analytical method results. The second models set were carried out by applying earthquake time history vertical acceleration for real past earthquake. Different profiles for stratified soil with variable stiffness have been considered in the analysis to investigate the increments in the seismic induced tunnel lining forces in terms of maximum thrust forces and bending moments.

From the study, the main conclusions drawn can be summarized as follows:

1) The critical location for the ground layers interface is where it crosses the tunnel lining near the crown.

2) For tunnels embedded in stratified ground with upper layer stiffer than lower layer causes increments in the tunnel lining seismic bending moments is 3 times more than the single layer model results and thrust forces are increases by $40 \%$.

3) Thin tunnel lining is more sensitive to soil stratification than thick ones.

4) No-slip condition assumption gives more conservative results than full-slip condition. However, based on this study the variation in the slippage conditions has no considerable effect on the tunnel seismic forces.

5) Tunnels built in stiff ground and intercept by thin softer layer subjected to seismic forces show increases of $80 \%$ in the maximum bending moment and $60 \%$ in thrust forces.

The study proved that tunnels built in multi layered soil required careful investigation. Further studies and improved models are needed to include other tunnel sizes, liner thicknesses, and non-linear soil behavior. Tunnel located in stratified rock may be need studies as well. 


\section{APPENDIX}

Internal forces of a circular liner due to $\mathrm{P}$-wave propagation, under no-slip and full-slip interface conditions can be given from the following equations [4]: The analytical solution deals with the analysis of circular tunnel due to P-wave propagation.

M lining bending moment

$\mathrm{T}$ lining axial thrust forces

I second moment of inertia

A cross sectional area

C compressibility ratio

F flexibility ratio

$$
\begin{gathered}
C=\left(\frac{E_{s}}{E_{l}}\right)\left(\frac{r}{t}\right) \frac{\left(1-v_{l}^{2}\right)}{(1+v)(1-2 v)} \\
F=\left(\frac{E_{s}}{E_{l}}\right)\left(\frac{r}{t}\right)^{3} \frac{2\left(1-v_{l}^{2}\right)}{(1+v)}
\end{gathered}
$$

\section{No-Slip Condition:}

Thrust force

$$
T=[K 3+K 4]\left(\frac{\sigma_{\max } \cdot r}{2}\right)
$$

Bending moment

$$
\begin{array}{r}
M=\mp\left[\frac{C(1-2 v)}{6 \mathrm{~F}} \mathrm{~K} 3+1-0.5 \mathrm{~K} 4\right. \\
-\mathrm{K} 6]\left(\frac{\sigma_{\max } \mathrm{r}^{2}}{2}\right)
\end{array}
$$

Full-Slip Condition:

Thrust force

$$
T=[K 3+K 5]\left(\frac{\sigma_{\max } \cdot r}{2}\right)
$$

Bending moment

$$
\begin{gathered}
M=\mp\left[\frac{C(1-2 v)}{6 F} K 3+K 5\right]\left(\frac{\sigma_{\max } r^{2}}{2}\right) \\
K 3=\frac{2(1-v)}{1+(1-2 v) C}
\end{gathered}
$$

Where:

$$
\begin{array}{lc}
K 4 & K 5=\frac{4(1-v)}{2 F+5-6 v} \\
=1 & \frac{(1-2 v)(1-C) F-0.5(1-2 v)^{2} C+2}{[(3-2 v)+(1-2 v) C] F+[0.5(5-6 v)](1-2 v) C+(6-8 v)} \\
K 6 & {[1+(1-2 v) C] F-[0.5(1-2 v) C]-2} \\
= & \frac{[(3-2 v)+(1-2 v) C] F+[0.5(5-6 v)](1-2 v) C+(6-8 v)}{}
\end{array}
$$

3. Gomes R, Gouveia F, Torcato D, Santos J. Seismic response of shallow circular tunnels in two-layered ground. Soil Dynamics and Earthquake $\begin{array}{llll}\text { Engineering, } & 75 & \text { (2015) } & \text { 37-43, }\end{array}$ http://dx.doi.org/10.1016/j.soildyn.2015.03.012.

4. Kouretzis G, Sloan S, Carter J. Analysis of circular tunnels due to seismic P-wave propagation with emphasis on unreinforced concrete liners. Computers and Geotechnics, 55 (2014) 187-194.

5. Kouretzis G, Sloan S, Carter J. Effect of interface friction on tunnel liner internal forces due to seismic $\mathrm{S}$ - and P-wave propagation. Journal of Soil Dyn Earthq Eng 46:41-51(2013).

6. Wang JN. Seismic design of tunnels-a simple state-of the-art design approach. Parson Brinckerhoff (1993), New York.

7. NHI-10-034. Technical manual for design and construction of road tunnel-civil elements. FHWA (2009).

8. Kontoe N, Avgerinos V, Potts D.M. Numerical validation of analytical solutions and their use for equivalent-linear seismic analysis of circular tunnels. Soil Dynamics and Earthquake Engineering 66 (2014) 206-219.

9. Peng Li, Song E. Three-dimensional numerical analysis for the longitudinal seismic response of tunnels under an asynchronous wave input. Computers and Geotechnics, 63(2015) 229-243.

10. Sedarat H, Kozak A. Contact interface in seismic analysis of circular tunnels. Tunneling and Underground Space Technology (2009) 24, 482-490.

\section{AUTHORS PROFILE}

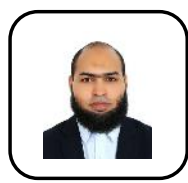

Amr I. Abdelaziz is a Senior Bridge/Structura Engineer at Omrania \& Associates, Saudi Arabia. He holds a BSc in civil engineering from Helwan University, Egypt, since May 2004. He received his MSc degree in structural engineering from Cairo University, Egypt in 2012. He has extensive experience in the reinforced concrete structures design. He participated in the design of many Bridges, Cut and Cover highway tunnels, high rise buildings up to 77 floors and reinforced concrete structures in Egypt, Saudi Arabia, Qatar, and United Arab Emirates. Currently he is a PhD student in Cairo University since October-2013 and looking forward to conduct many researches in the bridges and tunnels field.

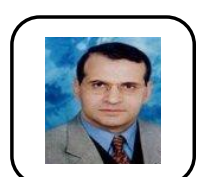

Osman O.M. Ramadan is Professor of structural engineering at Cairo University in Egypt since 2003, and is currently the Dean of Higher Technological Institute at the Tenth of Ramadan City in Egypt. He holds a Ph.D. in civil engineering from The University of Western

Ontario, Canada since 1993. His research activity is focused on static and dynamic soil-structure interaction analysis; and seismic response analysis of bridges, tunnels, and tall structures. Ramadan has authored and co-authored more than 70 scientific papers and technical reports in refereed journals and specialized conferences in the field of structural engineering. He is a board member of Egyptian Society of Civil Engineering (ESCE), has been serving as an active member in different committees responsible for the development of various specialized design codes for buildings and bridges in Egypt since 1997.

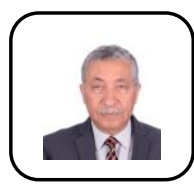

Adel Y. Akl has been a Professor of Structure Analysis and Mechanics since 1995 in Cairo University, Egypt, Faculty of Engineering, and Department of Structural Engineering. He received his $\mathrm{PhD}$ from NotreDamme University in 1984. His research has focused on soil structure interaction applications and numerical analysis using finite elements and infinite elements. He supervised more than 70 research students and published more than 50 research papers.

\section{REFERENCES}

1. ABAQUS/Standard - User's maval - version 6.17. Dassault Systems Simulia Corp.

2. Wang J.H, Tanaka H, Nakano M, Sugiyama H, Koizumi A, Chen F. Transverse seismic analysis of shield tunnel lining in multi-layered soft ground using different methods. 6th International Conference on Earthquake Geotechnical Engineering 1-4 November 2015 Christchurch, New Zealand. 